\title{
Mobile learning policy and practice in Africa: Towards inclusive and equitable access to higher education
}

\author{
Rogers Kaliisa \\ Department of Education, University of Oslo, Norway \\ Michelle Picard \\ University of Newcastle, Australia
}

\begin{abstract}
This article presents the results of a review of practice and policy in relation to mobile learning and its potential to enhance inclusive and equitable access to higher education in Africa. We reviewed academic literature on potential barriers. Then, we explored the current state of the mobile learning policy environment in 10 African countries through an analysis of how these policies have tried to address the prominent challenges in the adoption of mobile learning as identified in the literature. The findings reveal that significant resourcing inequalities and epistemological, sociocultural, and institutional barriers remain and affect mobile learning adoption. The analysis also reveals that there is still a policy vacuum in relation to mobile learning specific policies within African higher education institutional and governmental policies. Thus, the formal integration of mobile learning in higher education to facilitate equitable access is very much in its infancy. This article suggests a strong need for institutional, cross-institutional, national and African-wide mobile learning specific policies to ensure better implementation of mobile learning. As interest in mobile learning continues to grow, this review will provide insights into policy and strategic planning for the adoption of mobile learning to achieve inclusive and equitable access to higher education.
\end{abstract}

Implications for practice or policy:

- Relevant stakeholders such as decision makers in governments and higher educational institutions should play a more proactive role in developing explicit national and local mobile learning policies and guidelines to support inclusive and equitable access to higher education.

- The development of mobile learning policies needs to explicitly address and consider the intrinsic economic, social, regional, and gender inequalities existing within African countries.

Keywords: mobile learning, Africa, policy, equity, higher education

\section{Introductory background}

In 2015, more than 190 world leaders committed to 17 Sustainable Development Goals (SDGs) with an aim to end extreme poverty, fight inequality and injustice, and ensure environmental sustainability (United Nations, 2015). In this article, we focus on SDG 4 (Quality Education), which seeks to ensure inclusive and equitable education and promote lifelong learning opportunities for all. In particular, the article relates to Target 4.4 , which states that by 2030 , there should be access for all people to affordable and quality technical, vocational and tertiary education including university (United Nations, 2015). One of the reasons for Target 4.4 has been that progress towards greater participation in higher education has been extremely limited in sub-Saharan Africa in particular, with only $8 \%$ of the population accessing higher education in 2012 and significantly less in the poorest countries. Even in higher income African countries such as Ghana, South Africa, Kenya and Botswana, access has been skewed towards students from wealthier backgrounds and male students, with female students from poorer backgrounds having up to $35 \%$ less access than their male counterparts (Ilie \& Rose, 2016). 


\section{Higher education: Inclusivity and equitable access}

Although free higher education has been introduced in, for example, South Africa, this does not moderate the effects of low-income, remote location, or gender. In addition, prior social inequality results in many students not qualifying for higher education or needing to participate in extended programs to complete their degrees. The cost of books, materials, participation in extramural activities, transport and accommodation closer to the university are all significant, while the loss of income while studying fulltime results in many students needing to choose between books and food when budgeting their stipends, with students in extended programs experiencing extended hardship (Marginson, 2016; Walker, 2018). This has resulted in some claiming that free or highly subsidised higher education has just compounded disadvantage and resulted in more participation by middle class students but has done nothing to address the issue of inclusive participation in higher education for women, rural students, and students from lowincome families (Muller, 2018).

Another issue is that even if a student has access to higher education, this does not mean that their access will be equitable. Higher education is often stratified as it provides various levels of opportunity. Students from wealthier backgrounds most frequently attend elite universities to complete higher status professional degrees, and obtain qualifications with higher status, greater employment outcomes, and higher salaries on graduation. In contrast, students from poorer backgrounds tend to attend lower status institutions providing mass education of uncertain quality and outcomes. Thus, it is important to put in place policies and practice that limit the reproduction of social stratification in higher education (Marginson, 2016, pp. 421-432).

\section{Mobile technologies: Inclusivity and equitable access}

Mobile technology is another area where increased access has not necessarily led to equitable access and inclusivity, despite a number of efforts made in this regard. In February 2016 at the Mobile World Congress in Barcelona, the mobile industry became the first industry to commit to the SDGs (Bamberger, Segone, \& Tateossian, 2016). One key attribute that makes mobile technology important in the achievement of SDGs is its ubiquity (Traxler, 2010). For example, at the end of 2017, 3.3 billion people were connected to the mobile Internet, representing an increase of almost 300 million compared to the previous year. However, more than 4 billion people remain offline, and 1 billion of these are not covered by mobile broadband networks (Global System for Mobile Communications Association [GSMA], 2019. The 2019 report by the GSMA, a body that represents the interests of mobile operators worldwide, revealed that the mobile market in sub-Saharan Africa is growing faster than any other region of the world. In fact, its growth is increasing at numbers $50 \%$ higher than the global average. This is due to the increasingly affordable price of smartphones, which dropped from an average price of USD $\$ 230$ to USD \$160 in 2015 alone. Nonetheless, the same report highlights that sub-Saharan African countries continue to perform below the global average across both the index and the four enablers. The figures showed that sub-Saharan Africa has the highest percentage of areas not covered and not connected to mobile Internet (40\%) as compared to other regions with a 16\% (South Asia), 15\% (Middle East and North Africa region), 8\% (Latin America), 3\% (Europe), and 1\% (North America). However, despite the limited coverage, the GSMA report predicts that Africa will continue to lead mobile development for the next 5 years, which is critical for the achievement of SDGs since mobile Internet connectivity is widely associated with social and economic development, thus potentially providing a platform for increasing access to higher education (GSMA, 2019. In the developed world, the widespread diffusion of mobile technologies offers an opportunity to develop policies aimed at participation and social inclusion, given that the use of mobile devices transcends age, social status, economic level, gender, and ethnic origins (Arrigo, Kukulska-Hulme, Arnedillo-Sánchez, \& Kismihok, 2013). For example, in Australia, students with disabilities reported that the flexibility provided by mobile technologies enabled them to pursue educational opportunities, which could have been impossible at the traditional universities (Becker et al., 2017). However, this is not necessarily the case in the developing world. As noted above in relation to access to higher education, the significant economic, social, regional, and gender inequalities in Africa limit access to resources, including mobile technologies and data. 


\section{Mobile learning in higher education: Inclusivity and equitable access}

Given the increased use and penetration of mobile technologies including among the world's poorest regions, many believe that mobile technologies can contribute to making higher education more inclusive and equitable through mobile learning. In the context of this study, we define mobile learning as an approach that involves the use of mobile technologies, either alone or in combination with other information and communication technology (ICT) to support learning (Kraut, 2013; Traxler, 2010). A very broad definition of mobile learning has been selected to avoid missing any published literature relevant to this review. The potential of mobile learning for a more inclusive and equitable provision of higher education many researchers believe lies in its flexibility to provide high quality learning opportunities cheaply, anywhere anytime to people who might otherwise not be able to access it (Brown, Czerniewicz, \& Noakes, 2016; Hornsby \& Osman, 2014; Khalid \& Pedersen, 2016; Lumadi, 2017; Zozie \& Chawinga, 2018). Other scholars have praised the ability of mobile learning to foster learner independence through its ubiquitous access to educational materials (Becker et al., 2017; Handal, ElKhoury, Campbell, \& Cavanagh, 2013). Moreover, mobile learning has been considered by many researchers as the future of learning in Africa or as an integral part of any other form of educational process in the future (Kaliisa, Palmer, \& Miller, 2019).

Despite the many potential benefits of mobile learning for increasing access and equity in higher education, there have been only a few flagship large-scale projects implementing mobile learning for higher education in Africa. One of the notable examples is Kenya's Daystar University, which launched Daystar Mobile, a program in which students can earn a bachelor's degree in education primarily through their smartphones Moreover, Jibu, a mobile nursing education app, is helping health workers in Kenya, Uganda, and Tanzania to engage in ongoing training to maintain their professional licenses; while educational institutions also use the app to support student nurses in the field (Becker et al., 2017). However, the uptake of larger scale projects is limited. Back in 2006, Traxler and Leach noted that to be effective, development programs using mobile technologies needed to move away from small-scale uncoordinated projects to all stakeholders working with national ministries to embed change within policy across entire sectors. This has definitely not occurred in the higher education sector, with most universities developing their own ICT strategies, and when cross-institutional initiatives occur, this is usually with overseas partners with learning designed and delivered by the predominantly North American or European partners (Nafukho \& Muyia, 2013).

Research into the affordances of and barriers to mobile learning in encouraging greater equity and access has mainly been small scale, fragmented, and focused more on intentions to use rather than actual implementation (Kaliisa \& Picard, 2017). Moreover, previous studies have focused on understanding students and teachers' perceptions of mobile learning towards learning outcomes (Kaliisa \& Picard, 2017). In addition, most previous studies have focused primarily on uptake within higher education institutions without considering the broader economic, social inequalities that might shape this uptake. This strongly suggests that there is scope to undertake further investigation that focuses on the role of mobile learning towards the achievement of access and equity in higher education from the African perspective. Hence, we aim to draw together the disparate studies in order to gain an understanding of mobile learning with this specific focus. In addition, given the emphasis a number of authors (Aluko, 2017; Ghasia, De Smet, Machumu, \& Musabila, 2018; Ilomäki, Paavola, Lakkala, \& Kantosalo, 2016; Nafukho \& Muyia, 2013; Willems \& Bossu, 2012) place on the importance of sector-wide change driven by policy, it is important to place particular emphasis on the role of policy in mobile learning and equity.

Thus, the aim of this descriptive review is twofold. First, we aim to provide a critical analysis of challenges facing mobile learning adoption as identified in the literature. Secondly, we provide a theoretical insight into the understanding of the existing mobile learning policies and to critically assess the relevance of these policies in achieving inclusive and equitable access to higher education. Consequently, the study highlights the strengths and weaknesses of the current policy environment, thus providing a frame of reference for teachers and institutions, interested in designing mobile specific policies. 


\section{Methodology}

The methodology of this study is broadly a descriptive literature review. This methodology enables a systematic identification of gaps in current research, and a bridge between related areas of work (Torraco, 2016). The 5-stage descriptive review process consists of (a) problem formulation, (b) data collection or literature search, (c) evaluation of data, (d) data analysis, and (e) interpretation and presentation of results. As the first stage is described above, the following paragraphs describe the selection and evaluation criteria by which we selected the literature and evaluated the selected sources.

\section{Mobile learning, equity, and access in practice}

To respond to the first aim, we focused on equity and access and mobile learning as reflected in the academic literature. Using NeWCat, a university general database with over 300 journal databases, we used the following search terms:

- $\quad$ Equity AND mobile learning AND Africa

- Access AND mobile learning AND Africa.

After refining to peer reviewed journal articles, removing duplicates, and limiting the search to articles published between 2012 and 2019 in English and limiting to higher education as a topic, 200 articles were identified. After reading the articles, conducting a further Google Scholar search, and identifying articles from a previous review (Kaliisa \& Picard, 2017) that related to mobile learning in higher education in Africa, but were still relevant to equity, access, and mobile learning, the data was limited to 35 articles where all or some of them related to the project.

\section{Mobile learning policies}

To respond to the second aim and identify literature related to policy and their relevance in achieving equity and access through mobile learning, we conducted a literature search using Google Scholar and a university database called ORIA, which includes key international journal databases including ERIC and SCOPUS. We searched relevant literature using simple keywords including "mobile learning AND policy", "Mobile learning AND Africa", "mobile learning policies in Africa" and "ICT policies in Africa". However, these keywords and databases did not produce any policy on ICT or mobile learning. This is possibly because policies are rarely published in scholarly journals and databases. As a result, the authors conducted general searches in Google and websites of individual institutions of higher learning and ministries of ICT in the different African countries. In total, 12 ICT policies from 10 African countries and 2 higher educational institutions of learning were retrieved. The searches were conducted to include relevant policies published up to and including the 31st of May 2019 when the search was completed.

Table 1

Inclusion and exclusion criteria

\begin{tabular}{ll}
\hline Inclusion & Exclusion \\
\hline $\begin{array}{l}\text { The article/document identifies a mobile } \\
\text { learning/ICT policy }\end{array}$ & $\begin{array}{l}\text { Articles/documents not identifying ICT or mobile } \\
\text { learning policy }\end{array}$ \\
$\begin{array}{l}\text { The policy should be for one of the African } \\
\text { countries or higher institution of learning }\end{array}$ & Policies not specific to African countries \\
\hline
\end{tabular}

\section{Coding and categorisation}

The literature for the first aim was initially coded and categorised based on general challenges related to equity and access as well as challenges for specific equity groups including women, rural and remote inhabitants, and people with a disability as well as relying on the data for additional categories to emerge. The policies analysed to respond to the second aim were coded and categorised according to UNESCO's mobile learning policy guidelines, which are meant to support government education policymakers, practitioners, and key stakeholders in their efforts to develop and implement mobile learning programs and practices (West \& Vosloo, 2013. The guidelines provide an understanding of how the unique benefits 
of mobile learning (i.e., expanding and enriching educational opportunities) can be leveraged to advance progress towards Education for All (Kraut, 2013). Since the UNESCO guidelines are aimed at member states attempting to address a basic level of mobile learning provision, they have been viewed as appropriate for this study given the resource constraints of the context. However, the policy documents were also reviewed for any provision or innovation beyond the scope of the UNESCO guidelines. The policy documents were manually coded by the first author, and later cross-checked by both authors to ensure consistency. All differences in coding were discussed and reconciled. As well as primarily gaining guidance from the UNESCO mobile learning guidelines, the findings from the policy documents were also evaluated based on the limited studies on policy found in the initial search.

\section{Findings from the academic literature}

In this section, the data is described first according to general resourcing barriers to equitable access and inclusive access to higher education through mobile learning in Africa. Although the initial plan was to use the lens of various designated equity groups, extremely limited research has been conducted focusing on equity groups except for the three articles described below, which related to women. Therefore, instead, equity groups are discussed together in one section with further sections devoted to digital competence and/or epistemological access and institutional factors including staff-related factors.

\section{Resourcing barriers}

Although there has been a marked increase in mobile phone and device ownership across Africa as well as increased coverage by mobile networks, faster speeds, and lower comparative costs, the literature reveals that resourcing barriers remain a significant issue for higher education students and staff both onand off-campus. Limited bandwidth, weak local networks, and even electricity outages prevent students and staff in poorer countries from accessing mobile learning consistently even on campus (Ghasia et al., 2018; Gupta, Marsden, Oluka, Sharma, \& Lucas, 2017; Lwoga, 2012; Mugo, Ruto, Nakabugo, \& Mgalla, 2015; Oyelere, Paliktzoglou, \& Suhonen, 2016; Sanga, Magesa, Chingonikaya, \& Kayunze, 2013; Tarus, Gichoya, \& Muumbo, 2015; Zozie \& Chawinga, 2018). This situation is far worse for students in rural and remote areas with extremely patchy connectivity, limited bandwidth, and poor electricity supply for recharging devices. Even students in middle-income countries experience "digital exclusion" due to financial constraints limiting the purchase of mobile devices and data; as well as poor infrastructure in some local areas (Njeri Wachira \& Bosire Onyancha, 2016; Ololube, Agbor, Major, Agabi, \& Wali, 2016; Tarus et al., 2015). Due to these challenges, phone or other mobile device ownership is not necessarily synonymous with consistent access to online platforms and consequently consistent use (Lumadi, 2017; Lwoga, 2012). Even where there is access, the devices might not be appropriate for the learning purposes and/or the learners have not been taught to use them for learning purposes (Brown et al., 2016; Gachago et al., 2014; Heerwegh, De Wit, \& Verhoeven, 2016; Hornsby \& Osman, 2014; Ilomäki et al,, 2016; Nafukho \& Muyia, 2013; Waghid \& Waghid, 2016). Therefore, it is not sufficient to provide students who identify as lacking a mobile device with a device, but also to ensure that those who do own one have a compatible device and access to the necessary data and bandwidth (Brown et al., 2016; Brown \& Haupt, 2018; Waghid \& Waghid, 2016).

Another key resourcing issue is a lack of availability of high-quality content. Several studies have talked of the possible advantage of using international content including open educational resources and massive open online courses especially to support students in large classes by providing interactive content, scaffold learning, and activities where practical skills can be practised (Asamoah, 2017; Hornsby \& Osman, 2014; Leeds, 2013; Ng'ambi, Brown, Bozalek, Gachago, \& Wood, 2016; Shrivastava \& Shrivastava, 2014). However, the weakness of these resources is that they are often expensive and require licenses (Ghasia et al., 2018; Nafukho \& Muyia, 2013), they do not address local technical limitations such as limited bandwidth and take the capabilities of older mobile devices into account (Brown et al., 2016; Nafukho \& Muyia, 2013). Video streaming in particular is challenging in many rural African contexts (Gupta et al., 2017). In addition, the content is not necessarily locally relevant, and does not address the learning needs of students from equity groups (Aluko, 2017; Glass, Shiokawa-Baklan, \& Saltarelli, 2016; Leeds, 2013; Willems \& Bossu, 2012).

Mobile technologies have numerous affordances beyond searching for information via search engines and the provision of content portals (often described as Web 1.0 functionality) and peer-to-peer sharing of 
content and social networking (so-called Web 2.0 functionality). However, because of the resource and technological challenges mentioned above, as well as a lack of "digital competence" (Ilomäki et al., 2016), mobile learning opportunities are often limited to provision of content, access to content portals, and basic social networking (Gachago et al., 2014; Waghid \& Waghid, 2016; Zozie \& Chawinga, 2018). However, several scholars have identified that more sophisticated use of mobile technologies for learning purposes such as digital storytelling (Gachago et al., 2014) and video content creation (Brown et al., 2016) is possible if learners are provided with the devices, software, training, and web access required and they have flexibility in the way they address the tasks.

\section{Equity group barriers}

Besides the more general barriers described above relating to local resources and individual socioeconomic status which are heightened in the case of rural learners (Aluko, 2017; Chawinga \& Zozie, 2016; Sanga et al., 2013; Zozie \& Chawinga, 2018), the African literature is silent on other equity groups such as students with a disability, which receive prominence in the developed world. The specific access and equity challenge of women and mobile learning is, however, a topic addressed in several studies. Although mobile learning is viewed as having great potential to enable women to access higher education and science and technology resources and activities in particular (Dahya \& Dryden-Peterson, 2017; Sanga et al., 2013), this is not necessarily the case, and sometimes inequalities can even be compounded if faceto-face learning is replaced by online learning (Sanga et al., 2013). The literature reveals that it is not only important to provide women with devices but also learning opportunities that they can fit into their schedules as well as appropriate to different learning styles that emphasise social connections (Dahya \& Dryden-Peterson, 2017) or women students and even staff risk feeling excluded and stigmatised as "technophobic" (Lumadi, 2017, p. 12).

\section{Epistemological barriers}

As noted above in the case of women, the literature reveals that often e-inclusion is affected by a lack of "epistemological access" (Ghasia et al., 2018; Glass et al., 2016; Heerwegh et al., 2016; Hornsby \& Osman, 2014; Ilomäki et al., 2016; Khalid \& Pedersen, 2016; Ng'ambi et al., 2016). The content and nature of mobile learning might not resonate with the socio-economic background of the students. Consequently, as noted by Glass et al. (2016), two thirds of massive open online course learners are from North America and Europe and even in the remaining third of the world are predominantly male and white (Glass et al., 2016). Many students feel competent to use mobile phones for their own social purposes, but are not confident to use them for learning purposes (Brown \& Haupt, 2018; Ghasia et al., 2018; Heerwegh et al., 2016) and consequently "digital competence" (Ilomäki et al., 2016) can be a significant barrier to effective mobile learning that enhances equity and access in higher education.

\section{Institutional barriers}

Even when individual learners obtain greater access to mobile learning, institutional barriers remain which hamper individual access and greater exploitation of its affordances. The literature suggests that the attitudes of local staff are of particular importance. In general, there are positive attitudes towards the possibilities of mobile learning among staff (Brown et al., 2016; Hornsby \& Osman, 2014; Khalid \& Pedersen, 2016; Lumadi, 2017; Zozie \& Chawinga, 2018). However, there remains a significant number of staff who lack confidence and expertise and are even fearful of losing their jobs because of the introduction of mobile learning (Asamoah, 2017; Lumadi, 2017; Protsiv \& Atkins, 2016). Staff are also concerned about the high workload required to produce good digital content (Protsiv \& Atkins, 2016; Tarus et al., 2015). Another concern is that when external international content is used, local staff are relegated to being users rather than producers of content (Leeds, 2013; Nafukho \& Muyia, 2013) and their expertise is not valued or respected. University teachers are also fearful of the security of online material or learning activities with regard to plagiarism, confidential information, and unacceptable behaviours such as cyberbullying (Kaliisa et al., 2019; Oyelere et al., 2016).

The literature overwhelmingly suggests the importance of institution-wide, cross-institutional, national, and international collaborative processes and the importance of policy to ensure consistency and effective use of resources. For example, institutional policies privileging face-to-face teaching can result in a lack of appetite for mobile learning and a lack of updated documentation and training (Gupta et al., 2017;), 
and a lack of national and international policy guidance can result in a one-way communication from overseas providers and a lack of collaboration across institutions within countries. Thus, the following section on policy barriers is of particular importance.

\section{Findings from the policies and associated literature}

In this section, the analysis is divided according to the 10 guidelines of mobile learning policy proposed by UNESCO (West \& Vosloo, 2013). We summarise and appraise the existing ICT or mobile learning policies in 10 African countries and/or higher education institutions and assess how these intend to address digital equity challenges and inequalities within African higher education institutions. We also explored whether any of the policies moved beyond the UNESCO guidelines in recommending mobile learning provision. However, we could not identify any policies that went beyond the scope of the basic elements highlighted in the UNESCO guidelines.

\section{Create or update policies related to mobile learning}

The analysis of the existing policies revealed that there is still a policy vacuum in relation to mobile learning specific policies within African higher education institutional or governmental policies, as noted by Farrell (2007). For example, countries such as Rwanda, Uganda, Namibia, Kenya, Malawi, Nigeria, Ghana, and Senegal all have ICT policies but not specifically on mobile learning. A few exceptions were found in countries such as South Africa and Botswana, where policies that recognise the unique potentials offered by mobile learning have been created. Moreover, in Uganda, individual institutions such as Makerere University have policies on open, distance, and e-learning (ODeL), which emphasise among other elements the use of mobile learning to support distance education (Muyinda, 2012). Nonetheless, the recommendations for use of mobile learning mentioned in the general ICT for education policies largely remain written on paper but with limited translation into action. Simply put, the formal integration of mobile learning in higher education systems in Africa to facilitate access is very much in its infancy with most of the existing policies making reference to ICT in a general sense, hence a need to revise them to include mobile learning.

\section{Provide support and train teachers to advance learning through mobile technologies}

Teachers are key players in the implementation of educational technologies and any innovation that fails to take into account their needs (i.e., professional development) is bound to fail (Ferguson et al., 2016). This is even more relevant for mobile learning, which does not seem to be routinely established in the school or university curriculum, either as a delivery mechanism or as a subject at a national or institutional level. Thus, it is only through professional development that the use of mobile learning can be supported (Traxler \& Vosloo, 2014). The analysis of existing ICT policies and policy interventions showed that some countries have suggested relevant strategies to equip teachers with the necessary training. For example, in Uganda, the Connectivity for Educator Development project (set up computer centres and Internet points of presence at Kyambogo University and at eight primary teachers' colleges (Muyinda, 2012). In addition, Uganda's ICT policy highlights the need to strengthen existing IT training institutions and set up new IT centres of excellence in all districts in Uganda (Ministry of Information and Communications Technology, 2014). Elsewhere, in South Africa, educators have been provided with the necessary ICT training to promote mobile literacy through training initiatives, that is, the Meraka Institute, Microsoft, and the Vodacom Mobile Education Programme (Department of Higher Education and Training, 2014). In Kenya, the government developed national ICT competency standards for teachers (Kinuthia, 2009), while Namibia recommended the development of ICT training programs (Mary, 2006). Further, Botswana in partnership with Microsoft introduced a teacher training program on how to handle new digital learning tools (Thomas, 2010). Nonetheless, despite these initiatives and policy recommendations, we found that reference made to teachers' ICT training is generally related to computer use and is yet to leverage the potential of mobile technologies. Therefore, specific training in mobile pedagogies is needed. This is possibly why UNESCO took on the challenge to provide mobilespecific teacher training in countries such as Nigeria and Senegal to ensure the use of mobile technologies in pedagogically meaningful ways (Traxler \& Vosloo, 2014). However, there is an emphasis in support provided by these agencies on professional development for school teachers. University lecturers are rarely mentioned. This is perhaps why the latest EDUCAUSE Horizon Report: 2019 Higher Education Edition describes advancing digital equity as a "wicked challenge". In addition, the report notes that 
despite significant improvements in staff development, ensuring equitable and ongoing professional development between disciplines and for part-time staff, is a "difficult" challenge for the long term (Alexander et al., 2019).

\section{Create and optimise educational content for use on mobile devices}

One of the key challenges facing the adoption of mobile technologies is the lack of a mobile learning curriculum (Botha, Batchelor, Traxler, De Waard, \& Herselman, 2012) to support teachers in the delivery of meaningful and relevant educational content through mobile technologies (Kaliisa et al., 2019; Selwyn, 2008). As noted above, mobile devices tend to be used merely to store and access content, despite their versatility. In other words, navigating websites and learning management systems through mobile devices is often described as a nightmare by students (Farley et al., 2015). This is why UNESCO highlighted the need for mobile learning policies to recognise the need to create and optimise educational content and pedagogies for use on mobile devices (West \& Vosloo, 2013). In light of this, several initiatives were found in some African countries and higher educational institutions. One notable successful intervention is Rwanda's ICT masterplan, which among other initiatives has taken an effort to transform classes into smart classrooms where content is interactive through the use of mobile devices (Kozma \& Vota, 2014). In addition, the MobiClass pilot project at Makerere University was meant to develop a mobile learning content management system (m-learning application) (Muyinda, 2012), while in South Africa, initiatives such as the content development of interactive workbooks, Future Mobile Technology, and Dr. Math project were all aimed at developing mobile friendly curriculum at different levels of learning (Department of Higher Education and Training, 2014). In the meantime, Rwanda's ICT policy emphasises the development and acquisition of digital content, aligned with the curriculum, while in Tanzania, the BridgeIT initiative provides teachers with access to digital video content for on-demand screening in class via mobile technologies (Mwalongo, 2012). Another notable example is in Botswana, where the government through the Ministry of Education developed e-learning software that runs on Android with the potential to generate questions for students through their mobile devices (Thomas, 2010). However, despite an exhaustive search, no policy follow-up on these initiatives could be found and most interventions are largely small pilot projects, based at selected higher education institutions, and based on top-down rather than bottom-up creation of digital content. Consequently, there is limited focus on developing locally relevant mobile content, which affects the scaling of the existing initiatives beyond the pilot projects identified in some institutions.

\section{Ensure gender equality for mobile students}

As one of the ways to achieve gender equality, UNESCO emphasised the need for equal access to mobile devices for men and women, since research has shown that in today's increasingly connected world, women are being left behind (Kraut, 2013). For example, in the analysis based on findings from quantitative face-to-face surveys with men and women in Africa, the GISMA (2018) report on the mobile gender gap noted that while mobile connectivity is spreading quickly, it is not spreading equally in low- and middle-income countries, where women have less access to technology than men. Nonetheless, despite the need to ensure digital equity, the existing policies and interventions in the reviewed African countries have not progressed much in this area, with ICT policies referring to gender equality in a more general sense but with no practical interventions. For example, Uganda and Rwanda's ICT policies emphasise the need to put in place mechanisms to promote IT awareness and reduce the digital divide between men and women. However, we found no evidence of policy interventions to achieve this recommendation. This threatens to widen the inequalities women already experience, particularly in terms of access to higher education opportunities.

\section{Develop strategies to provide equal access for all, expand, and improve connectivity options while ensuring equity}

In line with the UNESCO Education for All (EFA) agenda, the concept of "mobile learning for all" focuses on the need to develop mobile learning interventions for those of all learning abilities around the world, irrespective of their current access to formal education (Winters, 2013). UNESCO recommends the need for governments to ensure equal access to mobile technology and participation in mobile learning for all students and teachers. This is especially important because adequate access to hardware and software is a prerequisite to dealing with the digital divide (Selwyn, 2008). In light of this 
recommendation, it was noticeable that none of the other African countries or institutions have implemented the provision of devices to students and teachers, with the exception of Rwanda, which initiated a One Laptop Per Child program that aims to provide 2.5 million children in primary school with learning devices (Fajebe, Best, \& Smyth, 2013); South Africa, which pledged the distribution of 365,000 laptops to all teachers and distribution of 88,000 Huawei tablets to 2200 schools in Gauteng province (Evoh, 2009); and Kenya, which distributed some tablets to selected schools through the Digital Literacy Programme (Piper, Jepkemei, Kwayumba, \& Kibukho, 2015) to ensure access to knowledge and content for all learners. The rest of the countries (i.e., Uganda) highlight the need to devise and implement a scheme for distributing affordable computers and Internet access to all academic institutions but this is yet to be achieved. Consequently, institutions interested in the provision of mobile learning could resort to having students using their own mobile device through the Bring Your Own Device model (Farley et al., 2015). However, even though this approach is already causing a major shift in higher education and distance learning by enabling more students to access course materials via mobile technology), studies have shown that many students lack the necessary devices to access mobile content (Kaliisa et al., 2019). For example, countries such as Ghana and Malawi reported to have very limited personal ownership of mobile phones (Porter et al., 2016). Moreover, the Bring Your Own Device approach favoured in developed countries could widen the inequality gap, where students with better mobile devices and connection could outperform those with no access to devices (West \& Vosloo, 2013). In addition, even if students receive devices at school or have their own devices, these may not provide viable options for mobile learning, as they are likely to be outdated by the time they attend university, resulting in the issues of compatibility described in Kaliisa and Picard's (2017) review.

\section{Promote the safe, responsible and healthy use of mobile technologies}

One challenge for the wide adoption of mobile learning in educational institutions is its risk of promoting undesirable behaviour such as bullying and sending violent messages (Porter et al., 2016) as well as health-related risks such as eye strain (Kaliisa et al., 2019). Another issue concerns teachers' access to students' phone numbers, which offers the potential for unprofessional conduct, as Porter and colleagues noted. This is why UNESCO urged policymakers to develop appropriate policies that promote the safe, responsible, and healthy use of mobile technologies. In accordance with this guideline, in Uganda, the ICT policy emphasises the need to review and ensure enforcement of cyber laws (Ministry of Information and Communications Technology, 2014). In South Africa, a set of e-safety guidelines to identify the ICTs currently used by school and university communities, (e.g., teachers and learners) were set up (Aluko, 2017; Porter et al., 2016). However, given the fact that students own devices and have private Internet subscriptions, there is a need for stricter policies to promote the responsible use of mobile devices through digital citizenship (Becker et al., 2017).

\section{Use mobile technology to improve communication and education management}

Mobile technology can be used in improving the communication and management of educational administration through tasks such as tracking attendance, registering students, and providing students with updates (Traxler \& Vosloo, 2014). This area of mobile technology use has witnessed some progress in African countries and higher education institutions. For example, in South Africa, a number of mobile applications for better classroom management are available (Department of Higher Education and Training, 2014) while in Uganda, applications such as Makerere University E-learning Environment (MUELE) were developed at Makerere University to improve communication between students and teachers (Muyinda, 2012).

\section{Raise awareness of mobile learning through advocacy, leadership, and dialogue}

The resistance towards mobile learning is usually associated with negative attitudes associated with the use of mobile technologies (Traxler \& Vosloo, 2014). One way to overcome this challenge is through policies that educate the public about the potential of mobile learning. However, there is currently little mention on issues of advocacy, leadership, and dialogue in line with mobile learning within the existing ICT policies. In other words, even though some mobile learning interventions have been implemented in some African countries, there is little evidence of success of these programs, yet this could be the benchmark to advocate for the application of mobile learning. 


\section{Implications and conclusion}

This article has provided a brief overview of a range of efforts made at individual higher education institutions as well as some cross-institutional efforts to implement mobile learning as a tool for greater equity and access, as reflected in the academic literature. The article also provides a brief overview of current policy efforts and interventions for mobile learning using 10 African countries as an example. The findings have revealed that there are policy and intervention attempts to support mobile learning, through the continued integration of digital content into the national curriculum and training of teachers in terms of using mobile technologies. Consequently, the existing ICT policies have established some guidelines and initiatives that are of value for reference, particularly for institutions and countries that are planning to develop their own local mobile learning policies and interventions.

However, significant resourcing inequalities, lacklustre mobile content, and epistemological, sociocultural, and institutional barriers remain, thus affecting mobile learning adoption to achieve inclusive and equitable access to higher education in the African context. Moreover, this review confirms that one of biggest challenges with the existing policies is their focus on ICT and the conventional models of e-learning in general, with little or no special consideration to mobile learning. In particular, most of the policies refer to mobile learning tangentially (Traxler \& Vosloo, 2014) with very limited focus on the practice of mobile learning. Consequently, as also noted by Isaacs (2012), evidence that informs policy development, decisions, and actions related to mobile learning still lacks credibility and trustworthiness and cannot yet be generalisable. Additionally, despite a few efforts to promote equal access to mobile learning and devices, we argue that current policy interventions have done little to overcome digital inequality. Even for countries that have tried to supply digital devices (i.e., Rwanda, South Africa, \& Botswana), this is only to a small group of students and teachers, thus, exacerbating digital inequalities with a big number of disadvantaged groups being digitally excluded. With this in mind, we argue that for mobile learning to grow and be scaled in higher education to address inequalities, relevant stakeholders such as decision makers in governments and higher educational institutions will need to play a more proactive role in developing explicit national and local mobile learning policies and guidelines, which can work as points of reference and a scaffold (Isaacs, 2012) particularly for educators who are interested in using mobile technologies in their everyday practice. Policies are the critical driving forces that underpin complex and systemic institutional problems and that shape perceptions of the nature of the problem(s) and acceptable solutions (Corvalán, Kjellström, \& Smith, 1999). Additionally, policies are funding instruments that determine priorities and allocation of the constrained resources available at higher education institutions in sub-Saharan Africa (Kaliisa et al., 2019). Therefore, even though policy improvements may not be quick fixes for all mobile learning challenges, it is only through the development of relevant, comprehensive, and explicit mobile learning policies that inclusive and equitable access to higher education through mobile learning can be achieved in African higher education. However, any policies for mobile learning need to explicitly address the intrinsic economic, social, regional, and gender inequalities existing in African countries. We hope that this article provides insight that can be used as a benchmark to develop more equitable mobile learning policies and interventions. Indeed, all the relevant stakeholders (i.e., teachers, students, administrators, parents, and telecommunication companies) should be brought on board so that concerns such as mobile safety, resistance, Internet access, and incompatible devices (Botha et al., 2012) are overcome. The intention of this review is to highlight areas policymakers can consider when updating the existing ICT policies or developing a new policy for mobile learning. This is to ensure that the implementation of mobile learning in higher education is appropriate and able to promote inclusive and equitable access among the most marginalised groups.

It should be noted, however, that the findings and recommendations presented in this article are by no means all encompassing. A small subset of publicly available policies from African countries and institutions of higher learning was retrieved from online sources. It is not clear whether these institutions have more detailed versions of policies that are not publicly available. The analysis presented here should therefore be regarded as illustrative rather than exhaustive. 


\section{Acknowledgements}

We thank the anonymous reviewers for their valuable comments on our manuscript. The first author received financial support from a $\mathrm{PhD}$ fellowship from the Faculty of Educational Sciences, University of Oslo, Norway.

\section{References}

Alexander, B., Ashford-Rowe, K., Barajas-Murphy, N., Dobbin, G., Knott, J., McCormack, ... Weber, N. (2019). EDUCAUSE Horizon Report: 2019 higher education edition. Louisville, CO: EDUCAUSE. Retrieved from https://library.educause.edu/resources/2019/4/2019-horizon-report

Aluko, R. (2017). Applying UNESCO guidelines on mobile learning in the South African context: Creating an enabling environment through policy. International Review of Research in Open \& Distance Learning, 18(7), 24-44. https://doi.org/10.19173/irrodl.v18i7.2702

Arrigo, M., Kukulska-Hulme, A., Arnedillo-Sánchez, I., \& Kismihok, G. (2013). Meta-analyses from a collaborative project in mobile lifelong learning. British Educational Research Journal, 39(2), 222 247. https://doi.org/10.1080/01411926.2011.652068

Asamoah, M. K. (2017). Access to undergraduate education is an unresolved burden in Ghana: A qualitative approach. International Journal of Lifelong Education, 36(5), 595-612. https://doi.org/10.1080/02601370.2017.1356880

Bamberger, M., Segone, M., \& Tateossian, F. (2016). Evaluating the Sustainable Development Goals: With a "no one left behind" lens through equity-focused and gender-responsive evaluations. New York, NY: ONU Mujeres, EvalGender+ y IOCE. Retrieved from https://www.evalpartners.org/sites/default/files/documents/evalgender/EN-Evaluating-SDG-web.pdf

Becker, S. A., Cummins, M., Davis, A., Freeman, A., Hall, C. G., \& Ananthanarayanan, V. (2017). NMC Horizon Report: 2017 higher education edition. Austin, TX: The New Media Consortium. Retrieved from https://www.learntechlib.org/p/174879/

Botha, A., Batchelor, J., Traxler, J., De Waard, I., \& Herselman, M. (2012). Towards a mobile learning curriculum framework. In P. Cunningham \& M. Cunningham (Eds.), Proceedings of the IST-Africa 2012 Conference (pp. 1-9). Retrieved from http://hdl.handle.net/10204/6057

Brown, C., Czerniewicz, L., \& Noakes, T. (2016). Online content creation: looking at students' social media practices through a connected learning lens. Learning, Media \& Technology, 41(1), 140-159. https://doi.org/10.1080/17439884.2015.1107097

Brown, C., \& Haupt, G. (2018). Using personal mobile devices to increase flexibility and equity in learning in resource-constrained contexts. Journal of Open, Flexible and Distance Learning, 22(2), 18-31. Retrieved from https://www.learntechlib.org/p/188232/

Chawinga, W. D., \& Zozie, P. A. (2016). Increasing Access to higher education through open and distance learning: Empirical findings from Mzuzu University, Malawi. International Review of Research in Open \& Distance Learning, 17(4), 1-20. https://doi.org/10.19173/irrodl.v17i4.2409

Corvalán, C. F., Kjellström, T., \& Smith, K. R. (1999). Health, environment and sustainable development: Identifying links and indicators to promote action. Epidemiology, 10(5), 656-660. Retrieved from http://www.jstor.org/stable/3703362

Dahya, N., \& Dryden-Peterson, S. (2017). Tracing pathways to higher education for refugees: the role of virtual support networks and mobile phones for women in refugee camps. Comparative Education, 53(2), 284-301. https://doi.org/10.1080/03050068.2016.1259877

Department of Higher Education and Training. (2014). DHET draft policy framework on distance education in South African universities 2012. Retrieved from https://www.che.ac.za/media_and_publications/documents-interest/dhet-draft-policy-frameworkdistance-education-south

Evoh, C. J. (2009). Emerging trajectories and sustainability of ICTs in educational reforms in Africa: Exploring the prospects of the teacher laptop policy in South Africa. Journal of Education for International Development, 4(2), 1-13. Retrieved from https://dev1.oerafrica.org/resource/emergingtrajectories-and-sustainability-icts-educational-reforms-africa-exploring

Fajebe, A. A., Best, M. L., \& Smyth, T. N. (2013). Is the one laptop per child enough? Viewpoints from classroom teachers in Rwanda. Information Technologies \& International Development, 9(3), $29-42$. Retrieved from https://www.itidjournal.org/index.php/itid/article/view/1088/445 
Farley, H., Murphy, A., Johnson, C., Carter, B., Lane, M., Midgley, W., \& Koronios, A. (2015). How do students use their mobile devices to support learning? A case study from an Australian regional university. Journal of Interactive Media in Education, 2015(1), art. 14. https://doi.org/10.5334/jime.ar

Farrell, G. (2007). Survey of ICT and education in Africa: Uganda country report. InfoDev ICT and Education Series. Washington, DC: World Bank. Retrieved from https://openknowledge.worldbank.org/handle/10986/10655

Ferguson, R., Brasher, A., Clow, D., Cooper, A., Hillaire, G., Mittelmeier, J., ... Vuorikari, R. (2016). Research evidence on the use of learning analytics: Implications for education policy. Seville, Spain: Joint Research Centre. https://doi.org/10.2791/955210

Gachago, D., Ivala, E., Barnes, V., Gill, P., Felix-Minnaar, J., Morkel, J., \& Vajat, N. (2014). Towards the development of digital storytelling practices for use in resource-poor environments, across disciplines and with students from diverse backgrounds. South African Journal of Higher Education, 28(3), 961-982. https://doi.org/10.20853/28-3-373

Ghasia, M. A., De Smet, E., Machumu, H., \& Musabila, A. (2018). Towards mobile learning deployment in higher learning institutions: A report on the qualitative inquiries conducted in four universities in Tanzania. Afrika Focus, 31(1), 115-132. https://doi.org/10.21825/af.v31i1.9042

Glass, C. R., Shiokawa-Baklan, M. S., \& Saltarelli, A. J. (2016). Who takes MOOCs? New Directions for Institutional Research, 2015(167), 41-55. https://doi.org/10.1002/ir.20153

Global System for Mobile Communications Association.(2019). The mobile economy: Sub-Saharan Africa 2019. Retrieved from https://www.gsma.com/subsaharanafrica/resources/the-mobile-economysub-saharan-africa-2019

Gupta, M., Marsden, S., Oluka, T., Sharma, R., \& Lucas, H. (2017). Lessons learned from implementing e-learning for the education of health professionals in resource-constrained countries. Electronic Journal of e-Learning, 15(2), 144-155. Retrieved from http://www.ejel.org/issue/download.html?idArticle $=577$

Handal, B., El-Khoury, J., Campbell, C., \& Cavanagh, M. (2013). A framework for categorising mobile applications in mathematics education. In Proceedings of the Australian Conference on Science and Mathematics Education (pp. 142-147). Retrieved from https://researchonline.nd.edu.au/edu_conference/70

Heerwegh, D., De Wit, K., \& Verhoeven, J. C. (2016). Exploring the self-reported ICT skill levels of undergraduate science students. Journal of Information Technology Education, 15, 19-47. https://doi.org/10.28945/2334

Hornsby, D., \& Osman, R. (2014). Massification in higher education: Large classes and student learning. Higher Education, 67(6), 711-719. https://doi.org/10.1007/s10734-014-9733-1

Ilie, S., \& Rose, P. (2016). Is equal access to higher education in South Asia and sub-Saharan Africa achievable by 2030? Higher Education, 72(4), 435-455. https://doi.org/10.1007/s10734-016-0039-3

Ilomäki, L., Paavola, S., Lakkala, M., \& Kantosalo, A. (2016). Digital competence: An emergent boundary concept for policy and educational research. Education \& Information Technologies, 21(3), 655-679. https://doi.org/10.1007/s10639-014-9346-4

Isaacs, S. (2012). Turning on mobile learning in Africa and the Middle East: Illustrative initiatives and policy implications (UNESCO Working Paper Series on Mobile Learning). Paris, France: United Nations Educational, Scientific and Cultural Organization. Retrieved from https://tostan.org/wpcontent/uploads/unesco turning on mobile learning in africa and the middle east.pdf

Kaliisa, R., Palmer, E., \& Miller, J. (2019). Mobile learning in higher education: A comparative analysis of developed and developing country contexts. British Journal of Educational Technology, 50(2), 546-561. https://doi.org/10.1111/bjet.12583

Kaliisa, R., \& Picard, M. (2017). A systematic review on mobile learning in higher education: The African Perspective. Turkish Online Journal of Educational Technology-TOJET, 16(1), 1-18. Retrieved from ERIC database. (EJ1124918)

Khalid, M. S., \& Pedersen, M. J. L. (2016). Digital exclusion in higher education contexts: A systematic literature review. Procedia - Social and Behavioral Sciences, 228, 614-621. https://doi.org/10.1016/j.sbspro.2016.07.094

Kinuthia, W. (2009). Educational development in Kenya and the role of information and communication technology. International Journal of Education and development using ICT, 5(2), 6-20. Retrieved from https://www.learntechlib.org/p/188086/

Kozma, R. B., \& Vota, W. S. (2014). ICT in developing countries: Policies, implementation, and impact. In Handbook of research on educational communications and technology (pp. 885-894). New York, NY: Springer. https://doi.org/10.1007/978-1-4614-3185-5 72 
Kraut, R. (2013). Policy guidelines for mobile learning: Paris, France: United Nations Educational, Scientific and Cultural Organization.

Leeds, B. (2013). Assessing the potential of OERs for ODL. South African Journal of Higher Education, 27(6), 1490-1507. Retrieved from https://hdl.handle.net/10520/EJC153339

Lumadi, M. W. (2017). Rethinking the technology platform through equitable quality curriculum for empowering the marginalised women in education. Koers: Bulletin for Christian Scholarship, 82(3), 1-13. https://doi.org/10.19108/KOERS.82.3.2326

Lwoga, E. (2012). Making learning and Web 2.0 technologies work for higher learning institutions in Africa. Campus-Wide Information Systems, 29(2), 90-107. https://doi.org/10.1108/10650741211212359

Marginson, S. (2016). The worldwide trend to high participation higher education: dynamics of social stratification in inclusive systems. Higher Education (00181560), 72(4), 413-434. https://doi.org/10.1007/s10734-016-0016-X

Mary, B. (2006). Using ICT for teacher professional development in Namibia. Washington, DC: World Bank. Retrieved from http://documents.worldbank.org/curated/en/121021468323958155/Using-ICTfor-teacher-professional-development-in-Namibia

Ministry of Information and Communications Technology. (2014). National information and communications technology policy for Uganda. Retrieved from https://ict.go.ug/2018/11/23/nationalict-policy/

Mugo, J. K., Ruto, S. J., Nakabugo, M. G., \& Mgalla, Z. (2015). A call to learning focus in East Africa: UWEZO'S measurement of Kenya, Tanzania and Uganda. Africa Education Review, 12(1), 48-66. https://doi.org/10.1080/18146627.2015.1036564

Muller, S. M. (2018, January 25). Free higher education in South Africa: Cutting through the lies and statistics. Mail \& Guardian. Retrieved from https://mg.co.za/article/2018-01-25-free-highereducation-in-south-africa-cutting-through-the-lies-and-statistics

Muyinda, P. B. (2012). Open and distance learning in dual mode universities: A treasure unexploited. In J. L. Moore \& A. Benson (Eds.), International perspectives of distance learning in higher education (pp. 33-50). Rijeka, Croatia: IntechOpen.

Mwalongo, A. (2012). Teachers' perceptions about ICTs for teaching, professional development, administration and personal use. International Journal of Education and Development using ICT, 7(3), 36-49. Retrieved from https://www.learntechlib.org/p/42357/

Nafukho, F. M., \& Muyia, M. H. (2013). The World Bank's Africa Virtual University Project: A revisit. European Journal of Training \& Development, 37(7), 646-661. https://doi.org/10.1108/EJTD-022013-0020

Ng’ambi, D., Brown, C., Bozalek, V., Gachago, D., \& Wood, D. (2016). Technology enhanced teaching and learning in South African higher education: A rearview of a 20 year journey. British Journal of Educational Technology, 47(5), 843-858. https://doi.org/10.1111/bjet.12485.

Njeri Wachira, M., \& Bosire Onyancha, O. (2016). Serving remote users in selected public university libraries in Kenya: perspectives of the section heads. Inkanyiso: Journal of Humanities \& Social Sciences, 8(2), 136-146. Retrieved from https://www.ajol.info/index.php/ijhss/article/view/153563

Ololube, N. P., Agbor, C. N., Major, N. B., Agabi, C. O., \& Wali, W. I. (2016). 2015 Global Information Technology Report: Consequences on knowledge management in higher education institutions in Nigeria. International Journal of Education \& Development using Information \& Communication Technology, 12(2), 4-25. Retrieved from https://www.learntechlib.org/p/173453

Oyelere, S. S., Paliktzoglou, V., \& Suhonen, J. (2016). M-learning in Nigerian higher education: An experimental study with Edmodo. International Journal of Social Media and Interactive Learning Environments, 4(1), 43-62. https://doi.org/10.1504/ijsmile.2016.075055

Piper, B., Jepkemei, E., Kwayumba, D., \& Kibukho, K. (2015). Kenya’s ICT policy in practice: The effectiveness of tablets and e-readers in improving student outcomes. In FIRE: Forum for International Research in Education, 2(1), 3-18. https://doi.org/10.18275/fire201502011025

Porter, G., Hampshire, K., Milner, J., Munthali, A., Robson, E., De Lannoy, A., \& Tanle, A. D. (2016). Mobile phones and education in Sub-Saharan Africa: From youth practice to public policy. Journal of International Development, 28(1), 22-39. https://doi.org/10.1002/jid.3116

Protsiv, M., \& Atkins, S. (2016). The experiences of lecturers in African, Asian and European universities in preparing and delivering blended health research methods courses: A qualitative study. Global Health Action, 9, 1-13. https://doi.org/10.3402/gha.v9.28149

Sanga, C., Magesa, M. M., Chingonikaya, E., \& Kayunze, K. A. (2013). Can e-learning promote participation of female students in STEM disciplines in higher learning institutions of Tanzania? 
International Journal of Education \& Development using Information \& Communication Technology, 9(3), 86-102.Retrieved from https://www.learntechlib.org/p/130277/

Selwyn, N. (2008). The use of ICT in education and the promotion of social inclusion: A critical perspective from the UK. Educação \& Sociedade, 29(104), 815-850. https://doi.org/10.1590/S010173302008000300009

Shrivastava, M., \& Shrivastava, S. (2014). Political economy of higher education: comparing South Africa to trends in the world. Higher Education, 67(6), 809-822._Retrieved from https://www.jstor.org/stable/43648692

Tarus, J. K., Gichoya, D., \& Muumbo, A. (2015). Challenges of implementing e-learning in Kenya: A case of Kenyan public universities. International Review of Research in Open \& Distance Learning, 16(1), 120-140. https://doi.org/10.19173/irrodl.v16i1.1816

Thomas, P. Y. (2010). Towards developing a web-based blended learning environment at the University of Botswana. (Doctoral dissertation). University of South Africa, South Africa. Retrieved from https://hdl.handle.net/10500/4245

Torraco, R. J. (2016). Writing integrative literature reviews. Human Resource Development Review, 15(4), 404-428. https://doi.org/10.1177/1534484316671606.

Traxler, J. (2010). Students and mobile devices. Research in Learning Technology, 18(2), 149-160. https://doi.org/10.1080/09687769.2010.492847

Traxler, J., \& Leach, J. (2006). Innovative and sustainable mobile learning in Africa. In the Fourth IEEE International Workshop on Wireless, Mobile and Ubiquitous Technology in Education (pp. 98-102). IEEE. https://doi.org/10.1109/WMTE.2006.261354

Traxler, J., \& Vosloo, S. (2014). Introduction: The prospects for mobile learning. Prospects, 44(1), 1328. https://doi.10.1007/s11125-014-9296-Z.

United Nations. (2015). Sustainable Development Goals. Retrieved from https://sustainabledevelopment.un.org/

Waghid, Z., \& Waghid, F. (2016). Examining digital technology for (Higher) Education through action research and critical discourse analysis. South African Journal of Higher Education, 30(1), 1-19. https://doi.org/10.20853/30-1-562

Walker, M. (2018). Dimensions of higher education and the public good in South Africa. Higher Education, 76(3), 555-569. https://doi.org/10.1007/s10734-017-0225-y

West, M., \& Vosloo, S. (2013). UNESCO, policy guidelines for mobile learning. Paris, France: UNESCO. Retrieved from https://unesdoc.unesco.org/ark:/48223/pf0000219641

Willems, J., \& Bossu, C. (2012). Equity considerations for open educational resources in the glocalization of education. Distance Education, 33(2), 185-199. https://doi.org/10.1080/01587919.2012.692051

Winters, N. (2013). Mobile learning in the majority world: A critique of the GSMA position. In S. Price, C. Jewitt, \& B. Brown (Eds.), The SAGE handbook of digital technology research (pp. 402-411). Thousand Oaks, CA: Sage. https://doi.org/10.4135/9781446282229.n27

Zozie, P., \& Chawinga, W. D. (2018). Mapping an open digital university in Malawi: Implications for Africa. Research in Comparative and International Education, 13(1), 211-226. https://doi.org/10.1177/1745499918761952

Corresponding author: Rogers Kaliisa,_rogers.kaliisa@iped.uio.no

Copyright: Articles published in the Australasian Journal of Educational Technology (AJET) are available under Creative Commons Attribution Non-Commercial No Derivatives Licence (CC BYNC-ND 4.0). Authors retain copyright in their work and grant AJET right of first publication under CC BY-NC-ND 4.0.

Please cite as: Kaliisa, R., \& Picard, M. (2019). Mobile learning policy and practice in Africa: Towards inclusive and equitable access to higher education. Australasian Journal of Educational Technology, 35(6), 1-14. https://doi.org/10.14742/ajet.5562 